\title{
Ortopedi ve Travmatolojide bilgilendirilmiş rıza
}

\author{
Informed consent in Orthopedics and Traumatology
}

\author{
Nezih Varol \\ Halk Sağlığı ve Adli Tıp Uzmanı, TOTBiD Sağlık Hukuku Kurulu Üyesi
}

\begin{abstract}
Sağlık hizmet sunumunda hukuka uygunluk şartları arasında önemli obje olan "Bilgilendirme" kavramı hakkında doğru bilgilere ulaşmak gereklidir. Sağlık çalışanı olarak tarihten gelen bir anlayış ile insan bedenine dokunma hakkı mutlaka kişinin rızasına dayanmalıdır. Ancak hayati tehlike arz eden acil durumlarda bu hak izinsiz kullanmaya dönüşür ki bu hekimlere tanınan çok özel bir “hak”"tır İzinsiz kullanma hakkına dayalı bile olsa "el atma sorumluluğu" mutlaka kişinin bilgilendirilmesine dayalı olmalıdır. Zira hasta yararına bir iş görme, bir risk üstlenme olarak kabul edilen hekim ile hasta arası ilişkideki vekalet sözleşmesinin ana unsuru yapılanların ispatı ile hasta yararıdır. Bu bağlamda yapılanların ispatı açısından tıbbi belgeler bilgilendirmenin ispatı için yeterli olabilir mi, bu konuda prosedürler nasıl hazırlanmalı, nasıl bir form kullanılmalı, imzalanan belgeler kim tarafından ne zaman imzalanmalı, içeriği nasıl olmalı? vb. sorulara yanıt arayarak konuyu Sağlık Hukuku boyutu ile ele alacağız.
\end{abstract}

Anahtar sözcükler: ortopedi ve travmatoloji; bilgilendirilmiş rıza

\section{BILGILENDIRME NEDIR?}

Sağlık hizmetlerinden faydalanma ihtiyacı bulunan bir kişi, alacağı sağlık hizmetini bilmedir. Bununla birlikte en kısa sürede en yüksek yararda hizmetten yararlanma hakkı adına, hastanın alacağı sağlık hizmetindeki müdahalelere ortak olabilmesi için bilgilendirilmesi, hekimler için doğal bir güvence niteliğindedir.

Kişinin bilgilendirilmesi temel haklarından birisidir.

Zira;

Kişi hiç bilmediği, hiç güç yetiremediği bir konu olan sağlık hizmeti sunumunda tam bir teslimiyet içinde bile kalsa, vücut bütünlüğüne karşı yapılan her türlü müdahalede üç temel değer dikkate alınmalıdır. ${ }^{[1]}$
It is necessary to reach the right concepts about the concept of information, which is an important object among the conditions of compliance with the law in health service provision. As a health worker, the right to touch the human body with an understanding from history must be based on the consent of the person. However, in the case of life-threatening emergencies, this right becomes unauthorized use, a very special right granted to physicians. The responsibility for confiscation, even if it is based on the right of unauthorized use, must be based on the information of the person. This is because the main element of the power of attorney agreement in the relationship between the physician and the patient, which is considered to be a job for the benefit of the patient and to assume a risk, is the benefit of the patient with the proof of the actions taken. In terms of proof of this, medical documents can be sufficient for proof of information, how to prepare procedures, how to use a form, who signed the documents when, how the content should be? We will consider the law with its dimension.

Key words: orthopedics and traumatology; informed consent
1. Sosyal devlet ilkesine bağ|ı "Sağlık Hakkı"

2. Vücut bütünlüğüne dokunmaya izin verme hakkı

3. Kendi geleceği üzerinde karar verebilme hakkı

Sağlık hakkı, Anayasa'mızın 56. maddesi ile güvence altına alınmıştır. ${ }^{[2]}$

\section{A. Sağlık Hizmetleri ve Çevrenin Korunması}

Madde 56 - Herkes, sağıklı ve dengeli bir çevrede yaşama hakkına sahiptir.

Çevreyi geliş̧tirmek, çevre sağlı̆̆ını korumak ve çevre kirlenmesini önlemek Devletin ve vatandaşların ödevidir.

Devlet, herkesin hayatını, beden ve ruh sağlı̆̆ı içinde sürdürmesini sağlamak; insan ve madde gücünde tasarruf

- Illetişim adresi: Nezih Varol, Sahrayıcedid Mah. Şehit Illhanlar Sok. Dumlu Apt. 7/3, Kadıköy, İstanbul

Tel: 0542 - 2421392 e-posta: nezihvarol@yahoo.com

- Geliş tarihi: 23 Aralık 2019 Kabul tarihi: 25 Aralık 2019 
ve verimi artırarak, işbirliğini gerçekleştirmek amacıyla sağlık kuruluşlarını tek elden planlayıp hizmet vermesini düzenler.

Devlet, bu görevini kamu ve özel kesimlerdeki sağlık ve sosyal kurumlarından yararlanarak, onları denetleyerek yerine getirir.

Sağlık hizmetlerinin yaygın bir şekilde yerine getirilmesi için kanunla genel sağlık sigortası kurulabilir.

10 Aralık 1948 tarihinde Birleşmiş Milletler Genel Kurulu'da 217 sayılı karar ile kabul edilen "Insan Hakları Evrensel Beyannamesi” 25. maddede Sağlık Hakkı ifade edilmiştir. ${ }^{[3]}$

\section{Madde 25}

1. Herkesin kendisinin ve ailesinin sağlık ve refahı için beslenme, giyim, konut ve tıbbi bakım hakkı vardır. Herkes, işsizlik, hastalık, sakatlık, dulluk, yaşlılık ve kendi iradesi dışındaki koşullardan doğan geçim sıkıntısı durumunda güvenlik hakkına sahiptir.

2. Anaların ve çocukların özel bakım ve yardım görme hakları vardır. Bütün çocuklar, evlilik içi veya evlilik dışı doğmuş olsunlar, aynı sosyal güvenceden yararlanırlar.

Vücut bütünlüğüne dokunmaya izin verme hakkı da Anayasa tarafından 17. madde ile güvence altına alınmıştır. ${ }^{[2]}$

\section{Kişinin Dokunulmazlığı, Maddi ve Manevi Varlığı}

Madde 17 - Herkes, yaşama, maddi ve manevi varlığını koruma ve geliştirme hakkına sahiptir. Tıbbi zorunluluklar ve kanunda yazılı haller dışında, kişinin vücut bütünlüğüne dokunulamaz; rızası olmadan bilimsel ve tıbbi deneylere tabi tutulamaz. Kimseye işkence ve eziyet yapılamaz; kimse insan haysiyetiyle bağdaşmayan bir cezaya veya muameleye tabi tutulamaz.

1219 sayılı Tababet ve Şuabatı San'atlarının Tarzı İcrasına Dair Kanun'un 70. maddesi sağlık çalışanlarına her türlü müdahale de rıza şartı getirmiştir. ${ }^{[4]}$

\section{Madde 70 - (Değişik: 23/1/2008-5728/38 md.)}

Tabipler, diş tabipleri ve diş̧iler yapacakları her nevi ameliye için hastanın, hasta küçük veya tahtı hacirde ise veli veya vasisinin evvelemirde muvafakatini alırlar. Büyük ameliyei cerrahiyeler için bu muvafakatin tahriri olması lazımdır. (Veli veya vasisi olmadığı veya bulunmadığı veya üzerinde ameliye yapılacak şahıs ifadeye muktedir olmadığı takdirde muvafakat şart değildir.) Hilafinda hareket edenlere ikiyüzelli Türk Lirası idarî para cezası verilir. Bu Kanunda yazılı olan idarî para cezaları mahallî mülkî amir tarafindan verilir.

Ayrıca Hasta Hakları Yönetmeliği'nde (HHY) hasta tedavilerindeki tıbbi müdahalelerde rıza alınması gerektiği 24. madde ile belirtilmiştir. ${ }^{[5]}$

\section{HHY Tıbbi Müdahalede Hastanın Rızası}

\section{Hastanın Rızası ve İzin}

Madde 24 - Tıbbi müdahalelerde hastanın rızası gerekir. Hasta küçük veya mahcur ise velisinden veya vasisinden izin alınır. Hastanın, velisinin veya vasisinin olmadığı veya hazır bulunamadığı veya hastanın ifade gücünün olmadığı hallerde, bu şart aranmaz.

Kanuni temsilci tarafindan muvafakat verilmeyen hallerde, müdahalede bulunmak tıbben gerekli ise, velayet ve vesayet altındaki hastaya tıbbi müdahalede bulunulabilmesi; Türk Medeni Kanunu'nun 272'nci (Ana ve baba, vazifelerini ifa etmedikleri takdirde hâkim, çocuğun himayesi için muktazi tedbirleri ittihaz ile mükelleftir) ve 431'inci (Sulh mahkemesi, azle tevessül ve inzibati cezadan maada, vesayet altındaki kimsenin menfaati için muktazi tedbirleri de ittihaz ile mükelleftir.) maddeleri uyarınca mahkeme kararına bağılıdır.

Kanuni temsilciden veya mahkemeden izin alınması zaman gerektirecek ve hastaya derhal müdahale edilmediği takdirde hayatı veya hayati organlarından birisi tehdit altına girecek ise, izin şartı aranmaz.

Ü̧̧üncü fikrada belirtilen ve hayatı veya hayati organlardan birisini tehdit eden acil haller haricinde, rizanın her zaman geri alınması mümkündür.

Rızanın geri alınması, hastanın tedaviyi reddetmesi anlamina gelir.

Rızanın müdahale başladıktan sonra geri alınması, ancak tıbbi yönden sakınca bulunmaması şartına bağlıdır.

Hasta Hakları Yönetmeliği'ne göre sağlık hizmetlerinden faydalanma ihtiyacı bulunan kimsenin bu sağlık hizmetine rıza verebilmesi için önce bilgilendirilmesi gerekmektedir.

Dünya Tabipleri Birliğinin uzun emeklerle ele aldığı ve sözleşmelere konu ettiği "Hasta Hakları" ülkemizde 1998 yılında yayınlanan Yönetmelik ile bilgilendirmenin ve rızanın nasıl alınması gerektiğine yönelik şekil şartları oluşturmuştur.

\section{іKINCI BÖLÜM}

\section{Sağlık Hizmetlerinden Faydalanma Hakkı Bilgi Isteme}

Madde 7 - Hasta, sağlık hizmetlerinden nasıl faydalanabileceği konusunda bilgi isteyebilir. Bu hak, hangi sağılk kuruluşundan hangi şartlara göre faydalanılabileceğini, sağlık kurum ve kuruluşları tarafindan verilen her türlü hizmet ve imkanın neler olduğunu ve müracaat edilen kuruluşta verilen să̆lık hizmetlerinden faydalanma usulünü öğrenme haklarını da kapsar.

Bütün sağılk kurum ve kuruluşları, hastayı birinci fikra uyarınca bilgilendirmek için yeterli teknik donanımı haiz birimi oluşturmak; bu birimde, hastaya kesin ve yeterli bilgi 
verebilecek nitelik ve ehliyete sahip personeli daimi olarak istihdam etmek ve hastanın ihtiyacı olan birimlere kolayca ulaşabilmesini temin etmek üzere, kuruluşun uygun yerlerinde bilgilendirici tabela, broşür ve işaretler bulundurmak gibi tedbirleri almak zorundadırlar.

\section{ÜÇÜNCÜ BÖLÜM}

\section{Sağık Durumu ile ilgili Bilgi Alma Hakkı Bilgilendirmenin Kapsamı}

Madde 15 - (Başlığı ile birlikte değişik: RG-8/5/201428994)

\section{Hastaya;}

a) Hastalığın muhtemel sebepleri ve nasıl seyredeceği,

b) Tıbbi müdahalenin kim tarafından nerede, ne şekilde ve nasıl yapılacağı ile tahmini süresi,

c) Diğer tanı ve tedavi seçenekleri ve bu seçeneklerin getireceği fayda ve riskler ile hastanın sağlığı üzerindeki muhtemel etkileri,

ç) Muhtemel komplikasyonları,

d) Reddetme durumunda ortaya çıkabilecek muhtemel fayda ve riskleri,

e) Kullanılacak ilaçların önemli özellikleri,

f) Sağlığı için kritik olan yaşam tarzı önerileri,

g) Gerektiğinde aynı konuda tıbbî yardıma nasıl ulaşabileceği, hususlarında bilgi verilir.

\section{Kayıtları Inceleme}

Madde 16 - Hasta, sağlık durumu ile ilgili bilgiler bulunan dosyayı ve kayıtları, doğrudan veya vekili veya kanuni temsilcisi vasıtası ile inceleyebilir ve bir suretini alabilir. Bu kayıtlar, sadece hastanın tedavisi ile doğrudan ilgili olanlar tarafından görülebilir.

\section{Kayıtların Düzeltilmesini İsteme}

Madde 17 - Hasta; sağlık kurum ve kuruluşları nezdinde bulunan kayıtlarında eksik, belirsiz ve hatalı tıbbi ve şahsi bilgilerin tamamlanmasını, açıklanmasını, düzeltilmesini ve nihai sağlık durumu ve şahsi durumuna uygun hale getirilmesini isteyebilir.

Bu hak, hastanın sağlık durumu ile ilgili raporlara itiraz ve aynı veya başka kurum ve kuruluşlarda sağlık durumu hakkında yeni rapor düzenlenmesini isteme haklarını da kapsar.

\section{Bilgi Vermenin Usulü}

\section{Madde 18 - (Değişik: RG-8/5/2014-28994)}

Bilgi, mümkün olduğunca sade şekilde, tereddüt ve şüpheye yer verilmeden, hastanın sosyal ve kültürel düzeyine uygun olarak anlayabileceği şekilde verilir.
Hasta, tıbbi müdahaleyi gerçekleştirecek sağlık meslek mensubu tarafindan tıbbi müdahale konusunda sözlü olarak bilgilendirilir. Bilgilendirme ve tıbbi müdahaleyi yapacak sağlık meslek mensubunun farklı olmasını zorunlu kılan durumlarda, bu duruma ilişkin hastaya açıklama yapılmak suretiyle bilgilendirme yeterliliğine sahip başka bir sağlık meslek mensubu tarafindan bilgilendirme yapılabilir.

Hastanın kendisinin bilgilendirilmesi esastır. Hastanın kendisi yerine bir başkasının bilgilendirilmesini talep etmesi halinde, bu talep kişinin imzası ile yazılı olarak kayıt altına alınmak kaydıyla sadece bilgilendirilmesi istenilen kişilere bilgi verilir.

Hasta, aynı şikayeti ile ilgili olarak bir başka hekimden de sağlık durumu hakkında ikinci bir görüş almayı talep edebilir.

Acil durumlar dışında, bilgilendirme hastaya makul süre tanınarak yapılır.

Bilgilendirme uygun ortamda ve hastanın mahremiyeti korunarak yapılır.

Hastanın talebi halinde yapılacak işlemin bedeline ilişkin bilgiler sağlık hizmet sunucusunun ilgili birimleri tarafindan verilir.

\section{Bilgi Verilmesi Caiz Olmayan ve Tedbir Alınması Gereken Haller}

Madde 19 - Hastanın manevi yapısı üzerinde fena tesir yapmak suretiyle hastalığın artması ihtimalinin bulunması ve hastalığın seyrinin ve sonucunun vahim görülmesi hallerinde, teşhisin saklanması caizdir.

Hastaya veya yakınlarına, hastanın sağlık durumu hakkında bilgi verilip verilmemesi, yukarıdaki fikrada belirtilen şartlar çerçevesinde tabibinin takdirine bağlıdır.

Tedavisi olmayan bir teşhis, ancak bir tabip tarafından ve tam bir ihtiyat içinde hastaya hissettirilebilir veya bildirilebilir. Hastanın aksi yönde bir talebinin bulunmaması veya açıklanacağı şahsın önceden belirlenmemesi halinde, böyle bir teşhis ailesine bildirilir.

\section{Bilgi Verilmesini Yasaklama}

\section{Madde 20 - (Değişik: RG-8/5/2014-28994)}

İlgili mevzuat hükümleri ve/veya yetkili mercilerce alınacak tedbirlerin gerektirdiği haller dışında; kişi, sağlık durumu hakkında kendisinin, yakınlarının ya da hiç kimsenin bilgilendirilmemesini talep edebilir. Bu durumda kişinin kararı yazılı olarak alınır. Hasta, bilgi verilmemesi talebini istediği zaman değiştirebilir ve bilgi verilmesini talep edebilir. 


\section{Rıza Olmaksızın Tıbbi Ameliyeye Tabi Tutulmama}

Madde 22 - Kanunda gösterilen istisnalar hariç olmak üzere, kimse, rızası olmaksızın ve verdiği rızaya uygun olmayan bir şekilde tıbbi ameliyeye tabi tutulamaz.

Bir suç işlediği veya buna iştirak ettiği şüphesi altında bulunan kişinin işlediği suçun muhtemel delillerinin, kendisinin veya mağdurun vücudunda olduğu düşünülen hallerde; bu delillerin ortaya çıkarılması için sanığın veya mağdurun tıbbi ameliyeye tabi tutulması, hakimin kararına bağlıdır.

Gecikmesinde sakınca bulunan hallerde bu ameliye, cumhuriyet savcısının talebi üzerine yapılabilir.

\section{BEŞINCI BÖLÜM}

\section{Tıbbi Müdahalede Hastanın Rızası}

\section{Hastanın Rızası ve İin}

\section{Madde 24 - (Değisşik: RG-8/5/2014-28994)}

Tıbbi müdahalelerde hastanın rızası gerekir. Hasta küçük veya mahcur ise velisinden veya vasisinden izin alınır. Hastanın, velisinin veya vasisinin olmadığı veya hazır bulunamadığı veya hastanın ifade gücünün olmadığı hallerde, bu şart aranmaz.

Kanuni temsilcinin rıasının yeterli olduğu hallerde dahi, anlatılanları anlayabilecekleri ölçüde, küçük veya kısıtı olan hastanın dinlenmesi suretiyle mümkün olduğu kadar bilgilendirme sürecine ve tedavisi ile ilgili alınacak kararlara katılımı sağlanır.

Sağlık kurum ve kuruluşları tarafindan engellilerin durumuna uygun bilgilendirme yapılmasına ve rıza alınmasına yönelik gerekli tedbirler alınır.

Kanuni temsilci tarafindan rıza verilmeyen hallerde, müdahalede bulunmak tibben gerekli ise, velayet ve vesayet altındaki hastaya tıbbi müdahalede bulunulabilmesi; Türk Medeni Kanununun 346'nc ve 487'nci maddeleri uyarınca mahkeme kararına bağlıdır.

Tıbbi müdahale sırasında isteğini açıklayabilecek durumda bulunmayan bir hastanın, tıbbî müdahale ile ilgili olarak önceden açıklamış olduğu istekleri göz önüne alınır.

Yeterliğin zaman zaman kaybedildiği tekrarlayıcı hastalıklarda, hastadan yeterliği olduğu dönemde onu kaybettiği dönemlere ilişkin yapılacak tıbbi müdahale için rıza vermesi istenebilir.

Hastanın rızasının alınamadığı hayati tehlikesinin bulunduğu ve bilincinin kapalı olduğu acil durumlar ile hastanın bir organının kaybına veya fonksiyonunu ifa edemez hale gelmesine yol açacak durumun varlığı halinde, hastaya tıbbi müdahalede bulunmak rızaya bağlı değildir. Bu durumda hastaya gerekli tıbbi müdahale yapılarak durum kayıt altına alınır. Ancak bu durumda, mümkünse hastanın orada bulunan yakını veya kanuni temsilcisi; mümkün olmadı̆̆ı takdirde de tıbbi müdahale sonrasında hastanın yakını veya kanuni temsilcisi bilgilendirilir. Ancak hastanın bilinci açıldıktan sonraki tıbbi müdahaleler için hastanın yeterliği ve ifade edebilme gücüne bağı olarak rıza işlemlerine başvurulur.

Sağlık kurum ve kuruluşlarında yatarak tedavisi tamamlanan hastaya, genel sağlık durumu, ilaçları, kontrol tarihleri diyet ve sonrasında neler yapması gerektiği gibi bilgileri içeren taburcu sonrası tedavi planı sağlık meslek mensubu tarafindan sözel olarak anlatılır. Daha sonra bu tedavi planının yer aldığı epikrizin bir nüshası hastaya verilir.

\section{Tedaviyi Reddetme ve Durdurma}

Madde 25 - Kanunen zorunlu olan haller dışında ve doğabilecek olumsuz sonuçların sorumluluğu hastaya ait olmak üzere; hasta kendisine uygulanması planlanan veya uygulanmakta olan tedaviyi reddetmek veya durdurulmasını istemek hakkına sahiptir. Bu halde, tedavinin uygulanmamasından doğacak sonuçların hastaya veya kanuni temsilcilerine veyahut yakınlarına anlatılması ve bunu gösteren yazılı belge alınması gerekir.

Bu hakkın kullanılması, hastanın sağlık kuruluşuna tekrar müracaatında hasta aleyhine kullanilamaz.

\section{Riza Formu}

Madde 26 - (Başlığı ile birlikte değişik: RG-8/5/201428994)

Mevzuatta öngörülen durumlar ile uyuşmazlığa mahal vermesi tıbben muhtemel görülen tıbbi müdahaleler için sağlık kurum ve kuruluşunca 15 'inci maddedeki bilgileri içeren rıza formu hazırlanır. Rıza formunda yer alan bilgiler; sözlü olarak hastaya aktarilarak rıza formu hastaya veya kanuni temsilcisine imzalatılır. Rıza formu iki nüsha olarak imza altına alınır ve bir nüshası hastanın dosyasına konulur, diğeri ise hastaya veya kanuni temsilcisine verilir. Acil durumlarda tıbbi müdahalenin hasta tarafindan kabul edilmemesi durumunda, bu beyan imzalı olarak alınır, imzadan imtina etmesi halinde durum tutanak altına alınır. Riza formu bilgilendirmeyi yapan ve tıbbi müdahaleyi gerçekleştirecek sağlık meslek mensubu tarafindan imzalanır. Verilen bilgilerin doğruluğundan ilgili sağlık meslek mensubu sorumludur. Rıza formları arşiv mevzuatına uygun olarak muhafaza edilir.

\section{Rızanın Şekli ve Geçerliliği}

Madde 28 - Mevzuatın öngördüğg̈ istisnalar dışında, rıza herhangi bir şekle bağıl değildir.

Hukuka ve ahlaka aykırı olarak alınan rıza hükümsüzdür ve bu şekilde alınan rızaya dayanılarak müdahalede bulunulamaz.

\section{Rızanın Kapsamı ve Aranmayacağı Haller}

Madde 31 - (Başlığı ile birlikte değişik: RG-8/5/201428994)

Rıza alınırken hastanın veya kanuni temsilcisinin tıbbi müdahalenin konusu ve sonuçları hakkında bilgilendirilip aydınlatılması esastır. 
Hastanın verdiği rıza, tıbbi müdahalenin gerektirdiği sürecin devamı olan ve zorunlu sayılabilecek rutin işlemleri de kapsar.

Tıbbi müdahale, hasta tarafindan verilen rızanın sınırları içerisinde olması gerekir.

Hastaya tıbbi müdahalede bulunulurken yapılan işlemin genişletilmesi gereği doğduğunda müdahale genişletilmediği takdirde hastanın bir organının kaybına veya fonksiyonunu ifa edemez hale gelmesine yol açabilecek tıbbi zaruret hâlinde rıza aranmaksızın tıbbi müdahale genişletilebilir.

Mevzuat bize bu konuda yol gösterici iken pratikte uygulama bulamamaktadır. Zira hasta yararına düşünme, hasta yerine düşünmek haline gelmesi günümüz pratiğinde görülen gerçeklerdir.

Böyle bir durumda hastaya yaklaşım, hastanın en kısa sürede en yüksek yararda hizmet alması değil, mevcut olanakların hastaya bir an önce kullanılması şekline dönüşmektedir.

Hastaya yaklaşımda esas olan hastalık davranışını bilmek ne kadar ütopik ise de mevcut olanakların kullanılmasında hasta iradesini öne çıkarmak hukuki bir zorunluluktur.

Bu noktada Ortopedi ve Travmatoloji uzmanı bir hekimin bilmesi gereken ana kavram şudur;

Hastanın, yapılan bilgilendirilme ve beden bütünlüğüne müdahale edilirken vereceği rıza ile geleceğini belirleme hakkını kullandığıdır.

Hasta haklarını korumak ve geliştirmek bir hekimin esas ödevidir. Hasta haklarını korumak hekimin saygınlığını arttırır, hastanın/kişinin verdiği rıza ile tedaviye ortak olması ile hizmetin kalitesi artar, tedavide başarı şansı yükselir, oluşan hasta memnuniyeti ile sadık hastalar yaratılır.

Uluslararası karşılaştırmalı hukukta hasta bilgilendirmesinde ortak nokta hekimin yükümlülügü olduğudur. Türkiye Cumhuriyeti Yüksek Mahkeme kararları da benzer şekilde aydınlatma yükümlülügüu olarak konuyu ele almış ve yüzlerce karar ile konunun önemine değinilmiş içtihatlar yaratılmıştır.

Bu noktada esas olan bu bilgilendirmenin nasıl yapılacağı, yapılan bilgilendirmenin her olguda yeterli olup olmadığına nasıl karar verilebileceği, ilerde bilgilendirmenin yeterli olmadığı iddiasına kimin karar vereceği gibi konular sağık hukukunun tartışma konuları olmuştur.

Bu makalede özellikle bu konular ele alınarak bilgi vermek amaçlanmıştır.

Ortopedi ve Travmatoloji pratiğinde iki çeşit hasta vardır. Travmaya bağlı acil hastalar, hastalıklara bağlı ağıı/uyuşma/hareket kısıtlığı gibi şikayetler ile başvuran terapötik hastalar.

Acil hastalarda vakanın ağırlığ, hayati tehlikenin fazla oluşu ile bilgilendirme arasında ters orantı vardır. Bilgilendirme ile kaybedilen zaman hasta zararı olabilmektedir. Burada esas olan hasta yararı dikkate alınarak üstlenilen riskin niteliğidir.

Bilgilendirme ile hastanın iradesini hizmete ortak etmek yerine, hasta yerine bilgi sahibi olan hekimin hasta yararına hızlı karar vererek söz konusu "vekalet sözleşmesi" ile hareket etmesidir.

Vekalet sözleşmesinin hukuki şartlarını (hasta yararına ve hasta iradesine uygun iş görme, risk üstlenme, nispeten bağımsızlık vb.) bu noktada iş görme unsurunda öne çıkarıp hastanın öncelikli yarar göreceği tıbbi müdahaleleri onun adına yapması gerekmektedir. Bu durumda bile hastaya mümkün olan bilgi verilmeli, hasta yakınlarının endişesi giderilmelidir.

Terapötik amaçlı aydınlatmada, öncelikle hastaya sağlık durumu hakkında ve sağlıklı yaşam için davranış ölçütleriyle ilgili bilgiler verilmelidir. Tıbbi müdahaleye etkisi olacak yan konular (sağlık kaynakları, tedavinin mali içeriği, hastane fiziki yapısı vb.) hakkında da bilgi alması sağlanmalıdır.

\section{BILGILENDIRMENIN ŞEKLi}

Hem ceza hukukunda hem de özel hukukta, tıbbi müdahalenin yapılmadan önce hasta rızasının alınması gereken şart olmakla birlikte, sözleşmesel sorumluluk açısından şekil şartı bulunmamaktadır. Özellikle özel hukukta iş görme bir edimi/borcu ifade ettiğinden Türk Borçlar Hukuku bu noktada yol gösterici olarak geçerlilik kuralının altını çizer. ${ }^{[6]}$

\section{Türk Borçlar Kanunu}

\section{B. Sözleşmelerin şekli}

\section{Genel kural}

Madde 12 - Sözleşmelerin geçerliliği, kanunda aksi öngörülmedikçe, hiçbir şekle bağlı değildir. Kanunda sözleşmeler için öngörülen şekil, kural olarak geçerlilik şeklidir. Öngörülen şekle uyulmaksızın kurulan sözleşmeler hüküm doğurmaz.

Sağlık hizmet sunumunda kalite standartlarını belirleyen prosedürler ve buna bağlı geliştirilmiş belgeler kliniklerin mevcut yapısı ile farklılıklar gösterebilmekle birlikte Sağlık Bakanlığı Sağlık Hizmetleri Genel Müdürlüğü Sağlıkta Kalite ve Akreditasyon Daire Başkanlığının yayınladığı "Sağlıkta Kalite Standartları Hastane" SKS 5. versiyon ile konuya uygulama açısından şekil getirmiş̧tir. ${ }^{[7]}$ 


\section{TANIMLAR}

Hasta Odaklılık: Sunulan tüm hizmetlerde, istek, ihtiyaç, beklenti ve değerleri dikkate alınarak hastanın teşhis, tedavi ve bakım hizmetlerinde aktif katılımının sağlanmasıdır
Rıza Belgesi: Uygulanacak tıbbi işleme ilişkin, işlemi yapacak sağlık personeli tarafindan hastaya aktarılan bilgilerin yer aldığı ve hastanın rızasını almak için oluşturulmuş dokümandır.

\begin{tabular}{|c|c|}
\hline Kod & Standart \\
\hline $\begin{array}{l}\text { HHD04 } \\
\text { Çekirdek }\end{array}$ & $\begin{array}{l}\text { Hasta ve/veya hasta yakını, hastaya sunulabilecek teşhis, tedavi, bakım hizmetleri, hasta sorumlulukları ile diğer hizmetler } \\
\text { hususunda bilgilendirilmelidir. }\end{array}$ \\
\hline Kod & Değerlendirme Ölçütü \\
\hline HHD04.01 & Ayaktan ve yatan hastalarda bilgilendirmenin nasıl yapılacağı ve bilgilendirmeye ilişkin kurallar belirlenmelidir. \\
\hline HHD04.02 & $\begin{array}{l}\text { Hasta/Hasta yakını, hastane tarafindan belirlenen kurallar doğrultusunda, ilgili hekim tarafindan sözlü olarak bilgilendirilmelidir } \\
\text { Hasta/Hasta yakını asgari aşağıdaki konularda bilgilendirilmelidir: } \\
\text { o Hastanın genel durumu } \\
\text { o Tedavi süreci } \\
\text { o Bakım uygulamalarının seyri } \\
\text { o Yapılması planlanan her türlü tıbbi müdahale }\end{array}$ \\
\hline HHD04.03 & Hasta/hasta yakınlarının bilgilendirilmesi sırasında hasta mahremiyeti sağlanmalıdır. \\
\hline HHD04.04 & $\begin{array}{l}\text { Hasta güvenliğini olumsuz etkileyen istenmeyen olayların meydana gelmesi durumunda, hasta veya hasta yakınının nasıl } \\
\text { bilgilendirileceği tanımlanmalıdır. }\end{array}$ \\
\hline Kod & Standart \\
\hline HHD05 & Her türlü tıbbi müdahale öncesinde hasta rızası alınmalıdır. \\
\hline Kod & Değerlendirme Ölçütü \\
\hline HHD05,01 & 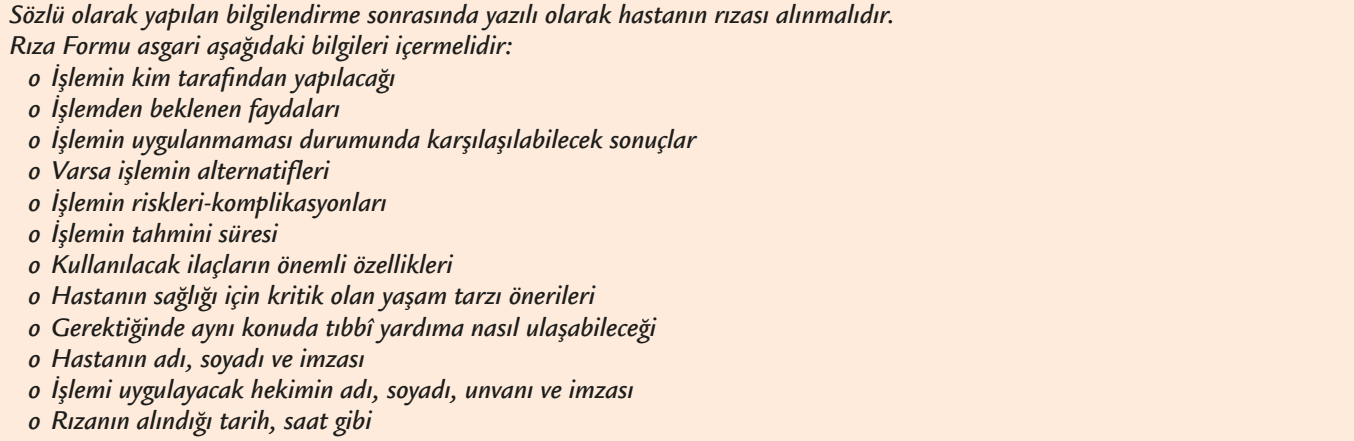 \\
\hline
\end{tabular}

\section{SONUÇ}

Ortopedi ve Travmatoloji uzmanları; yaptıkları tüm sağlık hizmet sunumunda hasta katılımını sağlamak, ortak iradeye onların da girmesini sağlamak adına hasta ve hasta yakınlarını bilgilendirmelidir.

Ortopedi ve Travmatoloji alanında uygulanan kalite standartlarını gözeterek hareket etmelidir.

$\mathrm{Bu}$ bağlamda kendi branşlarına yönelik prosedürleri bilmeli, güncellemeli, her olguda hasta yararını gözetmelidir.

Hastanın kendi geleceğini belirleme hakkına saygı göstermeli, hayati tehlikenin varlığında acil durumlarda bile hasta yararını düşünerek en hızlı kararı verirken mümkün olan bilgiyi hastaya verebilmelidir. ${ }^{[8]}$

\section{KAYNAKLAR}

1. Erman B. Tıbbi Müdahalelerin Hukuk Uygunluğu. Ankara: Seçkin Yayınları; 2003. s.57.

2. Türkiye Cumhuriyeti Anayasası. Erişim: https://www.mevzuat. gov.tr/MevzuatMetin/1.5.2709.pdf Erişim Tarihi: 24.10.2019.

3. BM İnsan Hakları Evrensel Beyannamesi, https://www. resmigazete.gov.tr/arsiv/7217.pdf Erişim Tarihi: 24.10.2019.

4. 1219 sayılı Tababet ve Şuabatı Sanatlarının Tarzı İcrasına Dair Kanun. Erişim: http://www.ttb.org.tr/ mevzuat/index.php?option=com_content\&view=article\& id=1014:1219-tababet-ve-uabati-sanatlarinin-tarzi-crasina-darkanun\&catid=1:yasa\&ltemid=28 Erişim Tarihi: 24.10.2019.

5. Hasta Hakları Yönetmeliği. Erişim: https://www.mevzuat.gov.tr/ Metin.Aspx?MevzuatKod=7.5.4847\&Mevzuatlliski=0\&sourceX mlSearch=hasta\%20haklar\%C4\%B1 Erişim Tarihi: 24.10.2019.

6. Türk Borçlar Kanunu. Erişim: https://www.mevzuat.gov.tr/ MevzuatMetin/1.5.6098.pdf Erişim Tarihi: 24.10.2019.

7. Sağlık Hizmetleri Genel Müdürlüğü, Sağlıkta Kalite ve Akreditasyon Daire Başkanlığı. Sağıkta KaliteStandartları- Hastane, 1. Revizyon, 2. Baskı. Ankara: Pozitif Matbaa; 2016. https://dosyahastane. saglik.gov.tr/Eklenti/7273,sks-saglikta-kalite-standartlari-2pdf.pd??0

8. Tacir H. Hastanın Kendi Geleceğini Belirleme Hakkı. İstanbul: Legal Kitabevi; 2011. 